Sharif University of Technology
Scientia Iranica
SCIENTIA
I RAN ICA
http://scientiairanica.sharif.edu

\title{
Response of buried oil and gas pipelines subjected to reverse faulting: A novel centrifuge-finite element approach
}

\author{
R. Yeganeh Khaksar, M. Moradi*, and A. Ghalandarzadeh \\ School of Civil Engineering, University College of Engineering, University of Tehran, Tehran, Iran.
}

Received 22 October 2016; received in revised form 1 January 2017; accepted 18 February 2017

\begin{abstract}
KEYWORDS
Steel buried pipeline;

Reverse faulting;

Centrifuge modeling;

Numerical modeling;

End connection.
\end{abstract}

\begin{abstract}
Buried pipelines through which fuels are transported inevitably face active faults when passing through various seismic regions. These faults may damage the pipelines severely; hence, numerous analytical, physical, and numerical studies were conducted with their own pros and cons to investigate the pipeline response due to the faulting. In the present study, an innovative combination of centrifuge and numerical modelling methods was employed to overcome the geometrical limitation of the small-scale physical modelling. Then, it was applied to investigate buried pipelines response due to reverse faulting. Initially, two centrifuge tests with the fixed end pipelines were conducted and employed as the benchmarks for the verification of a numerical model. Then, the calibrated numerical model was used to develop a novel pipeline spring-like end connection system, which is supposed to represent the response of the omitted pipeline parts. Eventually, a centrifuge test was conducted, employing a novel end connection system, which verified the proper performance of the system. Then, the model was employed to investigate the buried pipelines response due to reverse faulting, and the results were also presented.
\end{abstract}

(C) 2018 Sharif University of Technology. All rights reserved.

\section{Introduction}

Permanent Ground Deformations (PGDs) represent one of the most severe earthquake loadings on pipelines that would affect the structural integrity of buried pipelines [1]. Pipeline damages due to PGDs have been reported in various earthquakes all around the world. Therefore, numerous analytical, experimental, and numerical researches have been conducted on the matter.

Newmark and Hall [2] were one of the first researchers to develop a simplified analytical method

\footnotetext{
*. Corresponding author.

E-mail addresses: rezayeganeh@ut.ac.ir (R. Yeganeh

Khaksar); mmoradi@ut.ac.ir (M. Moradi);

aghaland@ut.ac.ir (A. Ghalandarzadeh).
}

doi: $10.24200 /$ sci. 2017.4214 to model intersection of a pipeline and a strike-slip fault. Kennedy et al. [3] extended the work of Newmark and Hall [2] through considering the effects of lateral interaction on the pipe-soil interface and the influence of large axial strains on the bending stiffness of the pipe. Wang and Yeh [4] modified the closed-form analytical model by employing the theory of beam to the elastic foundation to represent the pipelinesoil system. In addition, Meyersohn [5] investigated analytical considerations for the seismic response of buried pipelines. Takada et al. [6] presented a new simplified method for evaluating the critical strain of the fault crossing steel pipes. Kuwata et al. [7] studied the behavior of PVC and ductile iron pipelines using the Discrete Element Method (DEM) and proposed a method to estimate the allowable fault displacements. Vazouras et al. [8] investigated the mechanical behavior of the steel buried pipelines, crossing strike- 
slip faults through finite elements. They considered a soil-pipeline system with large displacements and nonlinear material behavior. Karamitros et al. [9] presented an analytical method for strength verification of buried steel pipelines at normal fault crossings. Vazouras et al. [10] proposed a simplified formulation for local buckling of pipeline wall crossing strike-slip faults. Xie et al. [11,12] conducted a comprehensive numerical modelling process of buried HDPE pipelines subjected to normal and strike-slip faulting. Zhang et al. [13] investigated bulking behavior of buried gas pipeline under strike-slip fault displacement by a finiteelement method and studied the effects of internal pressure, radius-to-thickness ratio, and fault displacement on buckling mode. Rahman and Taniyama [14] employed DEM and Finite-Element Method (FEM) to investigate the force-displacement relation between pipes and particles in the axial and vertical directions for fault movement. Vazouras et al. [15] developed a numerical model to extend their previous studies presented in $[8,10]$, accounting for appropriate end effects.

Moreover, Audibert and Nyman [16] and Takada [17] initiated experimental studies through the physical modelling of pipelines subjected to PGDs. Thereafter, a series of large- and small-scale models of pipelines subjected to strike-slip and normal faulting were carried out by O'Rourke et al. [18,19], Choo et al. [20], and $\mathrm{Ha}$ et al. [21-23]. More recently, Rojhani et al. [24,25] and Moradi et al. [26] conducted a series of centrifuge tests of pipelines subjected to normal and reverse faulting. In addition, Hojjat Jalali et al. [27] conducted full-scale experimental and numerical studies on the effects of reverse faulting on the buried gas pipelines. In all above experimental studies, either full-scale or centrifuge tests, the whole fault-affected length of pipe could not be modelled due to limitation of modelling length. Therefore, the interfering effects of end connections of a pipeline would appear in the model's response. In addition, some mitigation studies have also been conducted to lower the faultinduced pipelines. In this respect, Choo et al. [28] proposed a remediation technique for buried pipelines subjected to the strike-slip faulting using the expanded polystyrene (EPS) geofoam blocks as a low-density backfill; moreover, Melissianos et al. [29] numerically studied the effectiveness of an innovative flexible joint to mitigate the damages of faulting on pipelines.

To the best knowledge of the authors, solving such challenges of experimental models has not been paid enough attention yet, while it has somehow significant effect on the model response. In this regard, Vazouras et al. [30] developed a numerical model accounting for appropriate end effects. They combined their previously proposed numerical model with a closedform mathematical solution, investigating the behavior of the buried steel pipelines crossing the strike-slip faults. In addition, Zhang et al. [31] proposed a new finite-element model, considering the equivalent boundary spring, to simulate the interaction of the pipeline-soil beyond the model in strike-slip faults. In the current study, a hybrid approach to physical and numerical modelling was planned to tackle geometrical limitations of the centrifuge modelling of the pipe end connection's interfering effects on the response of the modelled pipe. Since the design of experiments may not include numerous centrifuge tests due to test expenses, two centrifuge models with fixed end pipes were conducted as benchmark tests to develop a validated finite-element model. Then, a pipeline end connection system has been developed for a reverse faulting mechanism based on the results of the calibrated numerical model. Eventually, the performance and reliability of the novel, developed end connection system have been verified through employing it in an extra centrifuge test. Such an approach could be a step forward in investigating various factors involved in pipelines subjected to reverse faulting, while the limitation of model length has been compensated.

\section{Physical modelling components}

In this study, the fault simulator introduced by Rojhani et al. [25] has been employed to carry out designed centrifuge tests with fixed end connections (Tests 1 and 2, Table 1). A centrifuge test has been also

Table 1. Centrifuge/prototype models' specifications.

\begin{tabular}{|c|c|c|c|c|c|c|c|c|c|c|c|c|}
\hline \multirow[t]{2}{*}{$\begin{array}{c}\text { Test } \\
\text { no. }\end{array}$} & \multirow[t]{2}{*}{ Model label } & \multirow[t]{2}{*}{$\begin{array}{c}\text { Fault } \\
\text { type }\end{array}$} & \multirow[t]{2}{*}{$\begin{array}{c}\text { Fault } \\
\text { angle } \\
\left({ }^{\circ}\right)\end{array}$} & \multirow[t]{2}{*}{$\begin{array}{c}\text { Cent. } \\
\text { acc. }^{a} \\
(\mathrm{~g})\end{array}$} & \multicolumn{2}{|c|}{$\begin{array}{c}\text { Peak } \\
\text { offset, } \\
U\end{array}$} & \multicolumn{2}{|c|}{$\begin{array}{c}\text { Pipe } \\
\text { diameter, } \\
D\end{array}$} & \multicolumn{2}{|c|}{$\begin{array}{c}\text { Pipe wall } \\
\text { thickness, } \\
t\end{array}$} & \multicolumn{2}{|c|}{$\begin{array}{c}\text { Burial } \\
\text { depth, } \\
H\end{array}$} \\
\hline & & & & & $\begin{array}{c}\mathbf{A}^{\mathrm{b}} \\
(\mathbf{m m})\end{array}$ & $\begin{array}{c}\mathbf{B}^{\mathrm{c}} \\
(\mathrm{m})\end{array}$ & $\begin{array}{c}\mathrm{A} \\
(\mathrm{mm})\end{array}$ & $\begin{array}{c}\mathbf{B} \\
(\mathbf{m})\end{array}$ & $\begin{array}{c}\mathbf{A} \\
(\mathrm{mm})\end{array}$ & $\begin{array}{c}\mathbf{B} \\
(\mathrm{mm})\end{array}$ & $\begin{array}{c}\mathrm{A} \\
(\mathrm{mm})\end{array}$ & $\begin{array}{c}\text { B } \\
(\mathbf{m})\end{array}$ \\
\hline 1 & R- -D25-T05-H40 & Reverse & $60^{\circ}$ & $40 \mathrm{~g}$ & 28.7 & 1.15 & 25 & 1.00 & 0.5 & 20.0 & 40 & 1.60 \\
\hline 2 & R- -D16-T04-H40 & Reverse & $60^{\circ}$ & $40 \mathrm{~g}$ & 29.5 & 1.18 & 16 & 0.64 & 0.4 & 16.0 & 40 & 1.60 \\
\hline 3 & R- -D25-T05-H40-S & Reverse & $60^{\circ}$ & $40 \mathrm{~g}$ & 38.0 & 1.52 & 25 & 1.00 & 0.5 & 20.0 & 40 & 1.60 \\
\hline
\end{tabular}

a Cent. acc.: Centrifuge Acceleration; ${ }^{\mathrm{b}}$ A: The small-scale centrifuge model; ${ }^{\mathrm{c}}$ B: The prototype model. 
conducted that employs the developed pipeline end connection system as the performance verification test (Test 3, Table 1). All tests have been carried out at a gravity level of $40 \mathrm{~g}$ horizontal acceleration that results in the magnitude of $1 / 40$ for the scaling of the centrifuge physical models to the prototype ones. The employed simulator was designed to model dipslip (normal and reverse) faulting in the geotechnical centrifuge with a soil container size of $960 \mathrm{~mm}$ (length) $\times 700 \mathrm{~mm}$ (width) $\times 230 \mathrm{~mm}$ (height). The device consists of a fixed part as the hanging wall and a movable one as the footwall, with the fault dip angle of $60^{\circ}(\beta)$. The faulting mechanism governs a fixed fault dip angle; therefore, Rojahni et al. [25] chose the convincing magnitude of $60^{\circ}(\beta)$ for dip angle, somehow similar to the specifications of other constructed simulators. The pipeline was buried perpendicular to the fault plane in a plan view due to the installed and constraint locations on the fault plane of container end walls.

\subsection{Pipe and soil specifications}

Generally, steel grades, such as X42, X52, X60, and X65 of API 5L, are selected for oil and gas pipelines in the industry. However, the available 304 grade stainless steel fine tubes were adopted as centrifuge modelling specimens in this study (Table 2, Figure 1), complying with ASTM Standard A999/A999M [32].

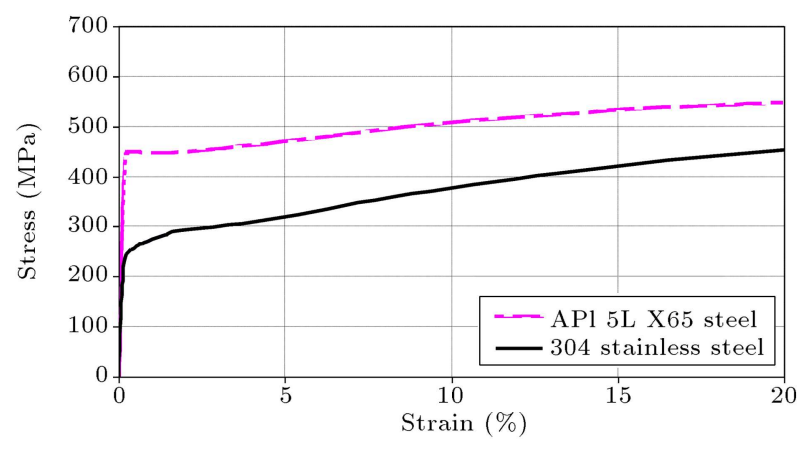

Figure 1. Stress-strain curves for API 5L X65 steel [8] and 304 stainless steel [33].
Buried pipelines are usually covered by polymer coating tapes in order to reduce the pipeline damages in general. Meanwhile, it appears that such coating plays a significant role in soil-pipeline interaction and should be considered. Herein, small-scale steel pipes have been also coated with scaled polymer coating tapes to simulate the real conditions. In order to obtain pipeline response data, the pipeline instrumentation (strain gauges) was placed on the pipeline surface underneath the applied coating tape. The soil was excavated to the designed depth, and the pipeline was placed down into the trench. Then, the replaced soil amount, minus the equivalent pipe volume, returned into the trench and compacted into the common relative density of $85 \%$ over the pipe. While complying with the criterion of Eq. (1), the Standard Firoozkouh 191 (SF191) sand was adopted as the surrounding soil:

$$
\mathrm{OD} / D_{50}>48
$$

where OD is the outer diameter of buried pipe, and $D_{50}$ is the mean grain size of the soil. Ovesen [34] and Dickin and Leuoy [35] derived such a criterion from centrifuge tests and issued it in the TC2-2005 [36]. Subsequently, a set of conventional laboratory tests (i.e., direct shear and compaction tests) was carried out to determine the properties of SF191 sand (Table 3).

In the present research, the soil water content (moisture) was considered $4.5 \% \sim 5.5 \%$, somehow representing the usual soil moisture of burial area in nature. In addition, the soil was compacted in $4 \mathrm{~cm}$-thick layers with the relative density of $85 \%$. The presence of the internal pressure is one of the factors affecting the compressive strain limit for steel pipes where it lowers the potential of local buckling and reduces the deformation capacity of the pipeline [10]. Gresnight [37] initially proposed the issue and presented a brief overview in their paper [38]. The aforementioned factor was adapted to CSA Z662 specification [39] and studied by Vazouras et al. [10]. In this study, the pipelines have been modelled with no internal pressure, and the

Table 2. Steel pipeline properties.

\begin{tabular}{cccccc}
\hline Steel type & $\begin{array}{c}\text { Density, } \\
\boldsymbol{\gamma}\left(\mathbf{k g} / \mathbf{m}^{\mathbf{3}}\right)\end{array}$ & $\begin{array}{c}\text { Poisson } \\
\text { Ratio, } \boldsymbol{v}\end{array}$ & $\begin{array}{c}\text { Young's modulus, } \\
\boldsymbol{E}(\mathbf{G P a})\end{array}$ & $\begin{array}{c}\text { Yield strength, } \\
\boldsymbol{F}_{\boldsymbol{y}}(\mathbf{M P a})\end{array}$ & $\begin{array}{c}\text { Ultimate strength, } \\
\boldsymbol{F}_{\boldsymbol{u}}(\mathbf{M P a})\end{array}$ \\
\hline Type 304 stainless steel & 8000 & 0.27 & 193 & 290 & 580 \\
\hline
\end{tabular}

Table 3. Standard Firoozkouh-191 sand mechanical properties.

\begin{tabular}{|c|c|c|c|c|c|c|}
\hline Sand type & $\begin{array}{c}\text { Density, } \\
\gamma \\
\left(\mathrm{kg} / \mathrm{m}^{3}\right) \\
\end{array}$ & $\begin{array}{c}\text { Poisson' } \\
\text { ratio, } \\
v \\
\end{array}$ & $\begin{array}{c}\text { Young's } \\
\text { modulus, } \\
E(\mathrm{MPa}) \\
\end{array}$ & $\begin{array}{c}\text { Friction } \\
\text { angle, } \\
\varphi\end{array}$ & $\begin{array}{c}\text { Cohesion, } \\
C \\
(\mathrm{kPa})\end{array}$ & $\begin{array}{c}\text { Dilation } \\
\text { angle, } \\
\psi\end{array}$ \\
\hline Firoozkouh 191 & 1550 & 0.3 & 10 & $35^{\circ}$ & 10 & $5^{\circ}$ \\
\hline
\end{tabular}




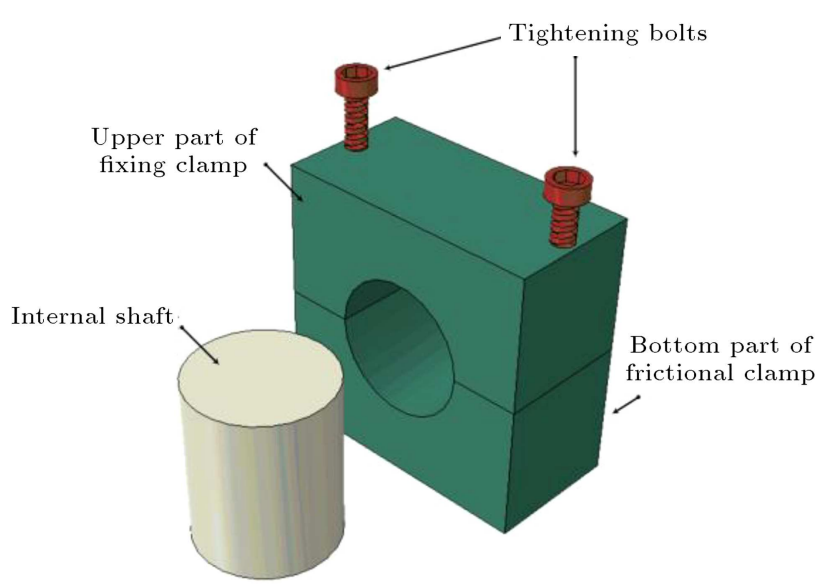

(a)

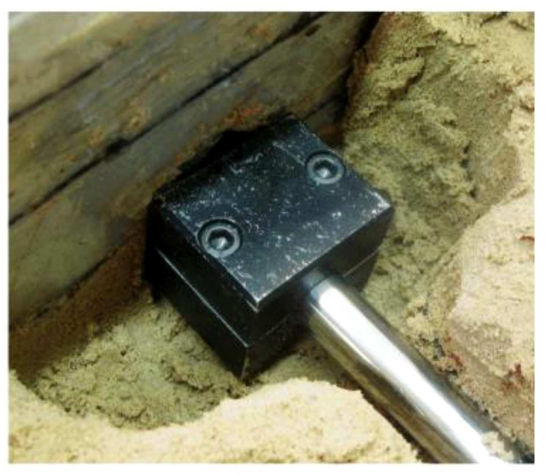

(b)

Figure 2. The fixing mechanism clamp: (a) Schematic picture of the clamp and its components and (b) the clamp used in experimental tests.

presence of internal pressure has been planned for the following steps of this study due to the requirement of further provisions and facilities in the centrifuge modelling.

\subsection{Pipeline end connection systems}

Since the affected length of pipe due to the faulting is generally more than the length of modelled pipe in the simulator box, fault-affected pipelines in centrifuge tests inevitably face the model length limitation. Since the long pipe could not be modelled in centrifuge tests to investigate the behavior of the modelled pipe, the pipeline end connections are of prime importance while investigating the response of pipelines due to faulting. In the tests reported by Rojhani et al. [24] and Moradi et al. [26], the pipes were anchored to the end walls using oxy-acetylene gas welding. The connections were considered fixed and assumed the last affected points of the pipeline subjected to the faulting, whereas such a welded area and the adjacent Heat Affected Zone (HAZ) would behave less ductile than the original pipe material. The comparison of the test results shown in Table 1 with those of Rojhani et al. [24] and Moradi et al. [26] confirmed the interfering effect of end connections (oxy-acetylene welded zone) on response and failure of the pipeline. Therefore, conducting complementary tests of Table 1 has the following outcomes: (1) evaluating the magnitude of the interfering effects of the welding end connections and (2) providing a set of pure pipeline material performance results that are described in the following.

\subsubsection{Fixing clamp}

In order to eliminate the interfering effect of the welded zone on steel pipeline behavior, the fixing clamp was designed in this study to replace the welding anchorage system proposed by Rojhani et al. [24]. The clamp was tied around the pipe and fixed to the split box wall, leaving no relative sliding between the pipe and clamp. A short length shaft with the exact diameter of pipe inner diameter also entered the pipe in the clamptied zone. The shaft prevented the local wrinkling occurrence in pipe wall when the clamp was tied. Such an end connection (Figure 2) was employed in the conducted tests of Table 1.

\subsubsection{Spring-like end connection}

Generally, the pipelines may experience neither fixed nor free joint/connection in any section along the faulting affected length in nature. Therefore, a semifixed end connection system with variable stiffness has to be made, representing the real behavior of the missing pipe length. To do so, a spring-like system with variable bending stiffness was developed in this study. The adopted stiffness would result in the desired longitudinal $\left(\Delta d_{h}\right)$, vertical transverse $\left(\Delta d_{v}\right)$, and rotational $(\theta)$ displacements of the pipeline ends according to the corresponding section in the fulllength model. Although simply assembled, the newly developed end connection system provides a chance to obtain the desired stiffness by varying the free span, thickness, and material of the spring strips. Since the spring strips were supposed to behave elastically, a series of loading tests (Figure 3 ) were conducted to obtain the elastic modulus of the employed CK75 spring steel strips for the following design simulation and calculations.

Moreover, the schematic pattern of the assembled spring-like end connection system is depicted in Figure 4.

Such a system had to be modified for conditions of each test based on the results of calibrated numerical models (see Section 3), hence expecting to represent the behavior of the entire fault-affected length of pipe, which inevitably was not modelled in previous conducted physical models. 


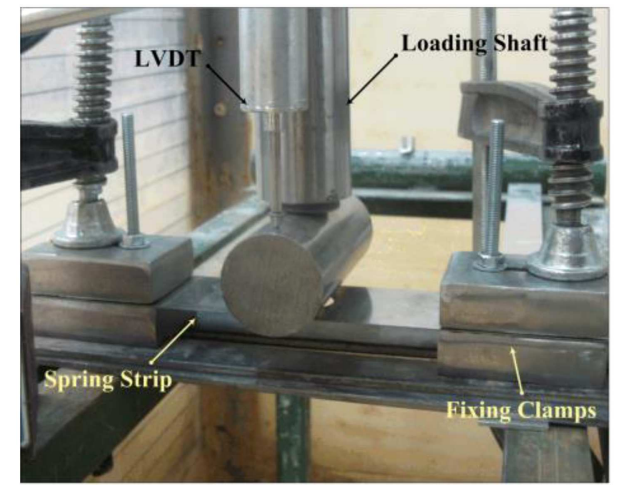

(a)

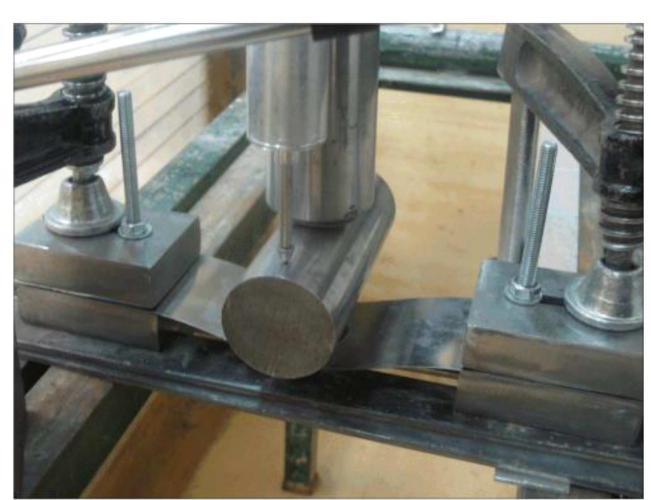

(b)

Figure 3. Spring steel strip loading tests before (a) and after (b) loading.

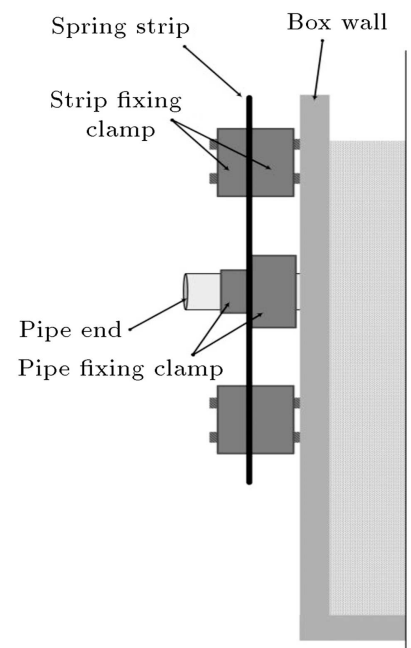

(a)

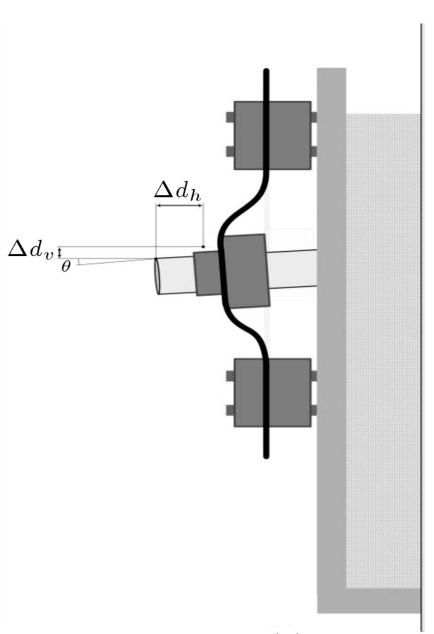

(b)
Figure 4. A schematic pattern for spring-like end connection systems: modifications to faulting before (a) and after (b) reverse faulting.

\subsection{Instrumentation}

In the conducted tests, data acquisition of model response has been performed via three methods. First, strain gauges have been installed on the top and bottom fibers of pipes at four to nine default locations. All the strain gauges have been set in a quarterbridge configuration to calculate axial and bending strains of the pipe. Moreover, the number of installed strain gauges has increased where large deformation or buckling in the pipe was expected. In order to obtain the chance to observe a soil disturbance pattern, the connecting wires of strain gauges were buried transversely to let the overburdened soil of the pipe remain undisturbed. Second, displacement transducers (LVDT) monitor the pipe and soil surface displacements. The wire LVDTs were employed to measure the downward and upheaval deformations of the pipeline in three locations. Two rod LVDTs were also used to acquire the soil surface displacements and an additional rod LVDT for logging box displacements. Third, an image processing technique was provided for which two cameras were employed to record the displacements of the end connection systems of springlike pipeline before, during, and after the faulting process. The first two types of instrumentation (strain gauges and LVDTs) were used in all conducted tests, while the image processing technique was solely employed in Test 3, Table 1. The general configuration of instrumentation array is depicted in Figure 5.

Moreover, colored sand layers were used between the soil layers in order to depict the layers deformation during the faulting.

\section{Numerical modelling}

Based on the specifications of the conducted centrifuge tests of Table 1 and the experiments reported by Rojhani et al. [24], a series of finite-element models were developed using the finite-element program ABAQUS [40]. In all numerical models of this study, the prismatic domain of soil, corresponding to the reference prototype model of centrifuge tests, was considered and, due to assumed $x-z$ symmetric plane, only half of the model was simulated [8]. The models include the pipeline, surrounding soil, and the soilpipe interaction. Tables 2 and 3 and Figure 1 provide the material properties for the steel pipe and the soil employed in the numerical models.

Faulting is categorized as a large deformation phenomenon. Therefore, the law for post-peak behavior of soil is of considerable influence. The faulting plane is an imposed one in this study, and no free propagation was observed according to the reference centrifuge tests. The dense sand of this study with approximate moisture content of $5 \%$ tends to undergo a strain softening behavior after yielding [41-43]. Based on the study conducted by Anastasopoulos et al. [42], an elastoplastic Mohr-Coulomb constitutive model with isotropic strain softening was adopted for the sand in this study 


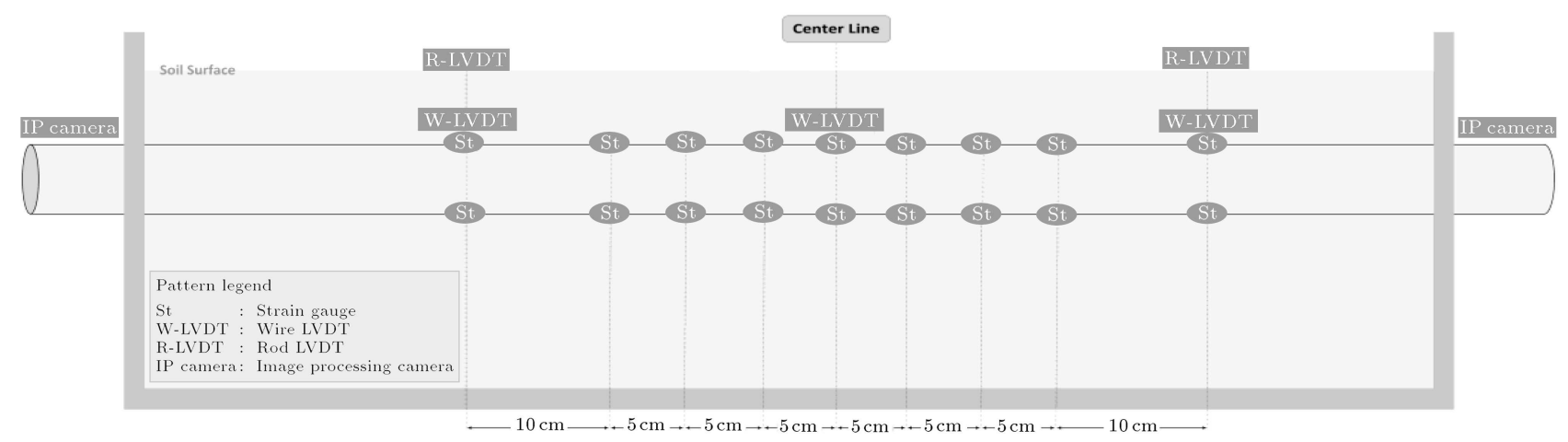

Figure 5. A general pattern of instrumentation array designed for the models.

through a user-defined subroutine in Abaqus. The direct shear test was employed to determine the model parameters for the Standard Firoozkouh 191 (SF 191) sand. Furthermore, a constitutive model of the elastic part reaching the yielding point, followed by a plasticity model with isotropic hardening, was utilized to describe the behavior of the steel pipe. The failure plane was predefined in this study according to the characteristics of the reference tests; therefore, the shear band evolution was assumed to happen along one element strip of $16 d_{50}$ width [44]. This led the shear bandwidth to be approximately $102 \mathrm{~mm}$ for the SF 191 sand in the centrifuge acceleration of $40 \mathrm{~g}$. Therefore, only the shear band mesh width was considered equal to $102 \mathrm{~mm}$, and the surrounding mesh generation followed a fine-to-coarse pattern going away from the fault plane. The soil-pipeline interaction was introduced by an interface friction law between the outer surface of the buried pipe and the surrounding soil. The values introduced for the pipe interface friction angle range from $20^{\circ}$ to the value of soil friction angle $\left(\phi_{\text {soil }}\right)[45]$. A numerical sensitivity study was conducted in this research to study the effect of sand-pipe friction angle variation on the response of model. The results showed that varying values within the above range would affect the pipe response slightly, as reported by Vazouras et al. [8] and Yimsiri et al. [45]. Therefore, the interface friction angle was regarded as $\phi_{\text {soil }} / 2$; eventually, the interface friction coefficient was set to the value of 0.32 , which also complied with Peng [47]. The element types used for soil continuum and pipeline included eightnode reduced integration solid (C3D8R) and four-node reduced integration shell (S4R), with a total number of 6240 and 3650 elements, respectively.

As stated before, the fault simulator has two separate parts with a relative movement where each part and its containing soil may have no relative displacement. Therefore, the boundary conditions of the box could be applied to the corresponding soil domain, according to the centrifuge apparatus mechanism. As the faulting velocity was generally low in the centrifuge tests $\left(V_{f} \approx 10 \mathrm{~cm} / \mathrm{s}\right)$, a nonlinear quasi-static approach was considered to be sufficient for the analysis. Moreover, the numerical analyses were performed in two steps: (1) Geostatic step in which the gravity loading was applied, and (2) Faulting step in which the fault rupture was imposed in a displacementcontrolled approach.

\subsection{Calibrated numerical model}

Initially, the developed numerical model was calibrated based on the results of the centrifuge tests of the present study (Table 1). The numerical model was developed according to the corresponding prototype model specifications of the above benchmark centrifuge tests. The meshed numerical model is depicted in Figure 6.

\subsection{Extended numerical model}

In the second step of numerical modelling, the developed calibrated model was extended longitudinally. The extension was done from the faulting plane to the length (approximately $400 D$ each side of the faulting plane) in which stresses and strains on the pipe would dissipate due to faulting. In such a case, the numerical model would represent almost the real behavior of the pipeline subjected to the faulting, and the desired displacements of the pipeline in the sections corresponding to the simulator box end connections could be determined. Such data of displacements for the box end connection regions were employed to design a proper configuration of spring-like end connection systems.

\subsection{Numerical modelling including "spring-like end connection" system}

In the final step of numerical modelling, a model including the spring-like end connection systems was developed. The desired displacements of the end connections $\left(\Delta d_{h}, \Delta d_{v}\right.$, and $\left.\theta\right)$ were obtained by varying the end connection system bending stiffness through changing the free span and spring strip thickness in a numerical parametric study. In other words, specifications of the spring strips constantly change 


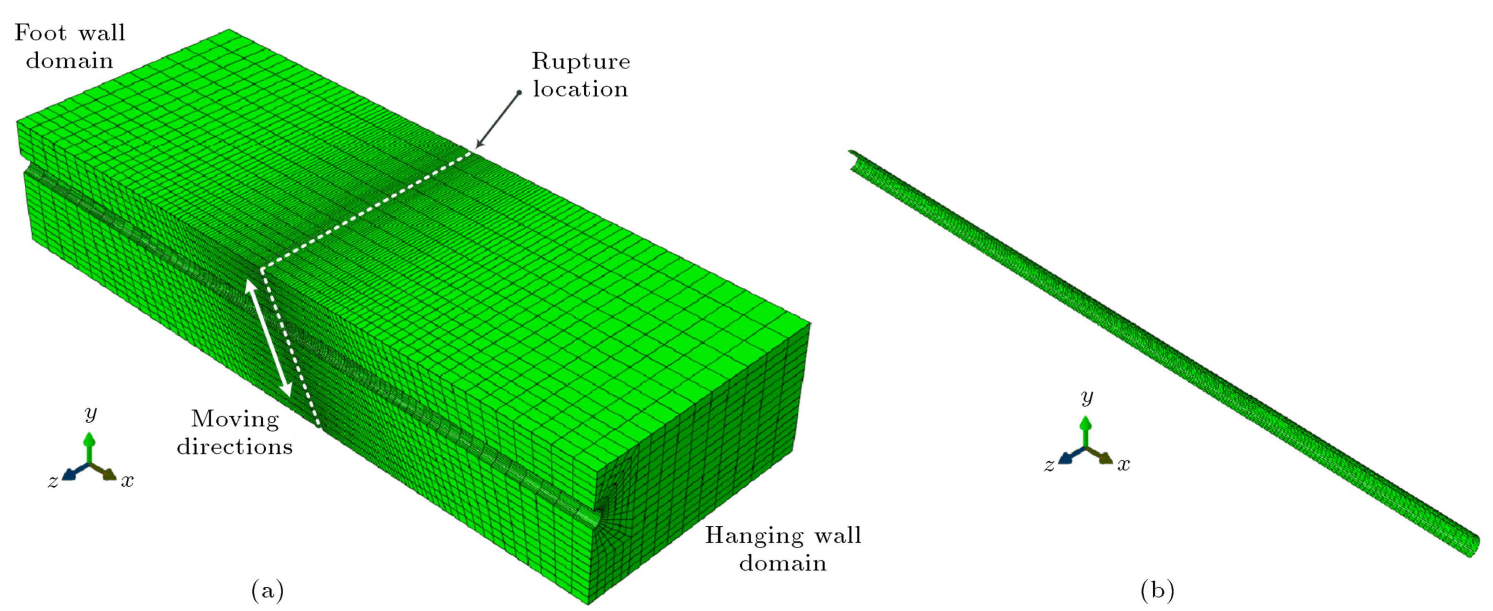

Figure 6. The finite-element model: (a) Soil domain and rupture location, and (b) buried steel pipeline.
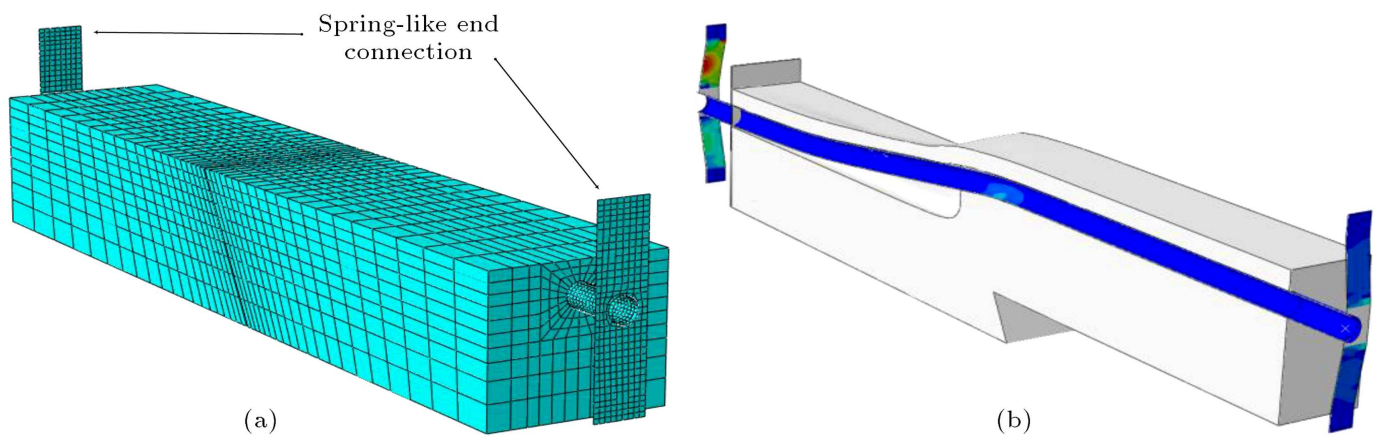

Figure 7. (a) The numerical model including "spring-like end connection" system. (b) The model response after subjecting to reverse faulting.

until obtaining the corresponding displacements. A picture of the developed model is depicted in Figure 7.

Considering the entire investigation process, an overview of the employed procedure in this research is briefly depicted in the following chart of Figure 8.

\section{Results and discussion}

\section{1. "Fixed end" centrifuge tests}

As indicated in Table 1, two tests have been conducted on the reverse faulting mechanism. In the following, the observations of the physical and mechanical behavior of the model are discussed.

\subsubsection{Post-offset observations}

Reverse faulting as a large ground deformation can put the buried pipelines into compression and bending and cause the buckling mode of failure. The shallow buried pipes with a smaller diameter tend to experience "beam buckling" where larger-diameter pipes buried deeper may behave like shells, given the name of "shell buckling", and result in "wrinkling" [48]. The buried pipes of the two reverse faulting tests (Tests 1 and 2, Table 1) showed somehow both two mentioned different behaviors. In Test 1, the soil surface disturbance occurred in the footwall zone, showing that the pipeline probably tended to experience beam buckling. However, the buckling zone in Test 2 has migrated to the hanging wall zone and caused the wrinkling of the

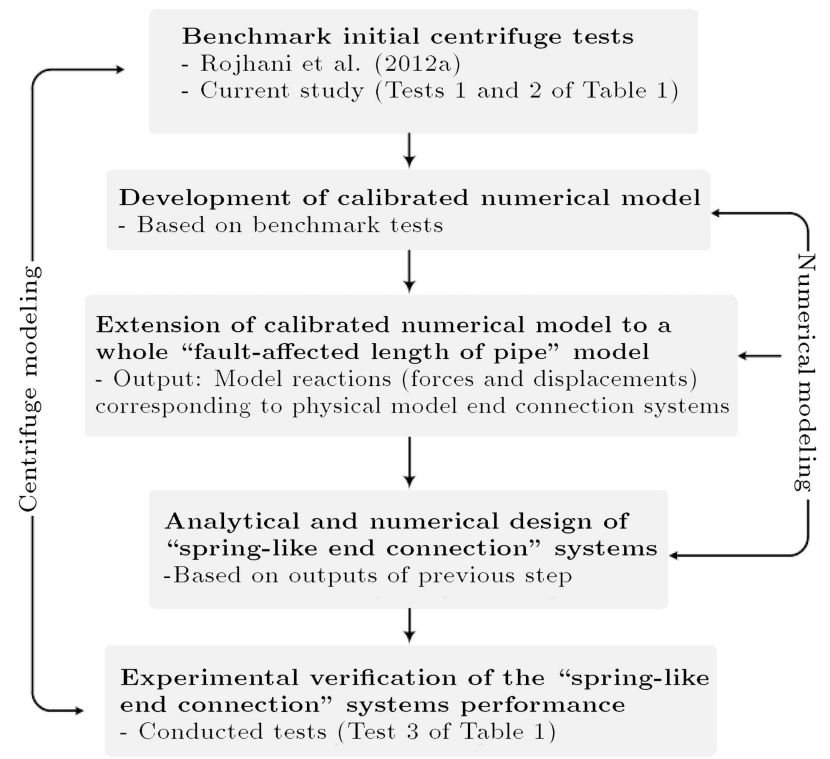

Figure 8. A small diagram of the procedure adopted within the present study. 


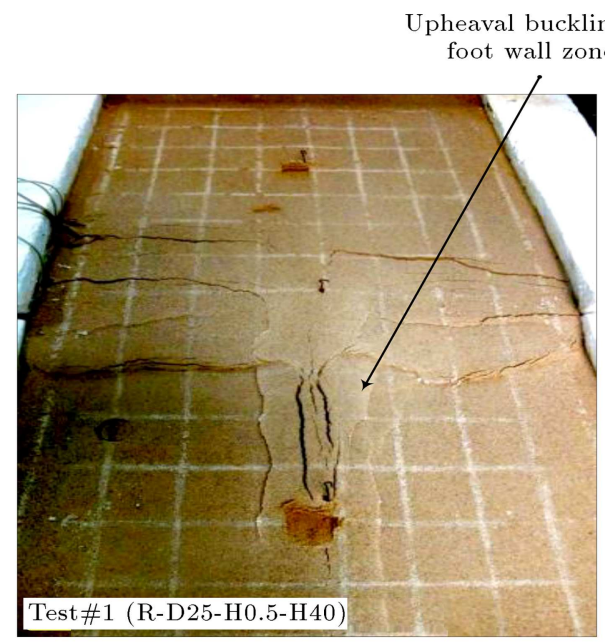

(a)

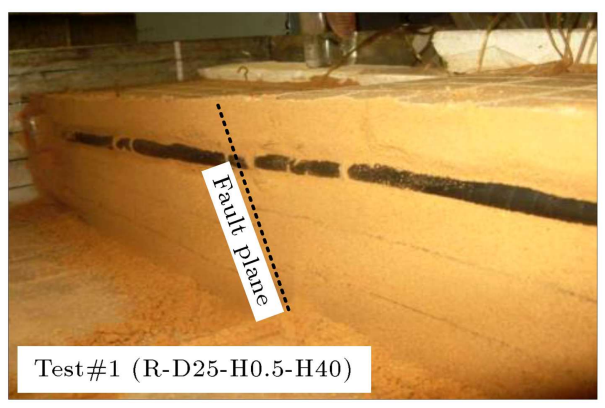

(c)

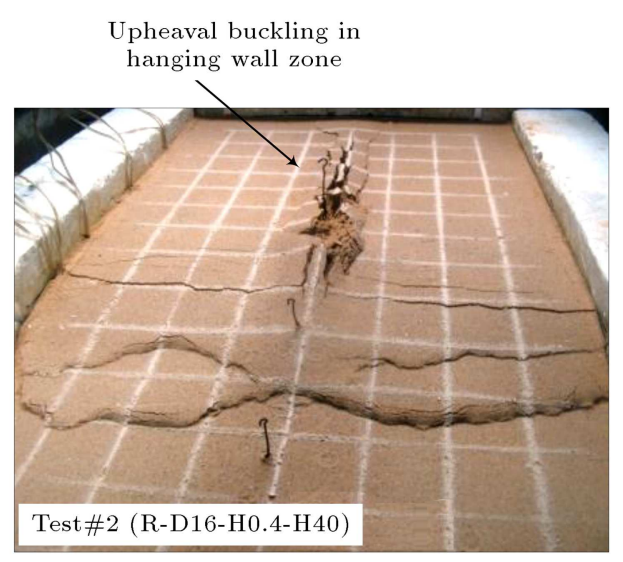

(b)

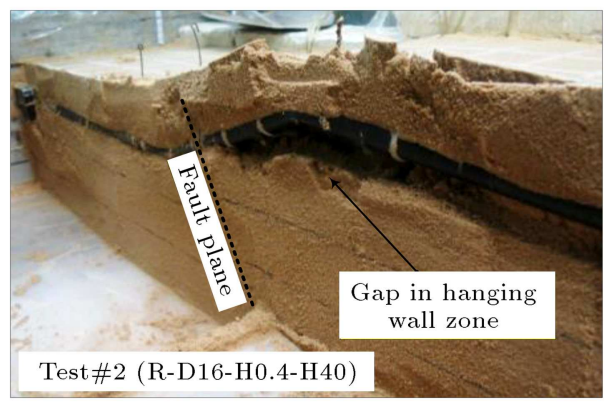

(d)

Figure 9. Soil disturbance in surface $(\mathrm{a}, \mathrm{b})$ and section view $(\mathrm{c}, \mathrm{d})$ due to reverse faulting.

pipeline (Figure 9). The burial depth of the pipe in both Tests of 1 and 2 was more than the critical cover depth of the pipe, which was proposed by Meyersohn [48] as a limit margin between beam and local buckling. In addition, the compressive strain of the pipeline in Test 2 passed the critical strain limit stated in CSA Z662 specification [39] according to Table 4. Therefore, the pipe in Test 1 was also supposed to experience local buckling, whereas this phenomenon did not happen obviously. This could reveal that, apart from the parameter introduced by Meyersohn [48] which was pipe wall thickness to diameter $(t / D)$, some other factors might also affect the occurrence of such a phenomenon (wrinkling). Herein, such undefined factors could be introduced as "relative burial depth" defined as the ratio of burial depth to the diameter of the pipe $(H / D)$ and, also, "relative fault displacement" defined as the ratio of fault displacement to the diameter of the pipe $(U / D)$. Considering such factors, the pipe in Test 1 (Table 1) might experience the beam buckling mechanism, although meeting the criterion proposed by Meyersohn [48]. The investigation of the factors affecting the critical burial depth could be done in detail in the future. By investigating the buckling initiation and propagation through the pipeline, a pattern could be considered to develop and evolve

Table 4. Comparison of pipeline compressive limit strains with the tests results.

\begin{tabular}{|c|c|c|c|c|c|c|}
\hline \multirow[t]{2}{*}{ No. } & \multirow[t]{2}{*}{ Guideline/st udy } & \multirow[t]{2}{*}{ Criterion } & \multicolumn{2}{|c|}{ Test $1(D=25 \mathrm{~mm})$} & \multicolumn{2}{|c|}{ Test $2(D=16 \mathrm{~mm})$} \\
\hline & & & Limit & Occurred & Limit & Occurred \\
\hline 1 & ALA guideline $[50]^{*}$ & $0.5 \mathrm{t} / \mathrm{D}-0.0025^{*}$ & $0.75 \%$ & & $1.0 \%$ & \\
\hline 2 & CSA-Z662 Specification [39] & $0.5 \mathrm{t} / \mathrm{D}-0.0025^{* *}$ & $0.75 \%$ & Bot. fiber $\simeq 0.36 \%$ & $1.0 \%$ & Bot. fiber $\simeq 1.18 \%$ \\
\hline 3 & Wijewickreme et al. [51] & $0.4 \mathrm{t} / \mathrm{D} \sim 2.4 \mathrm{t} / \mathrm{D}^{* * *}$ & $0.8 \% \sim 4.8 \%$ & & $1.0 \% \sim 6.0 \%$ & \\
\hline
\end{tabular}

* Operable strain limit for oil and gas pipeline systems in the absence of internal pressure.

** Ultimate strain limit for oil and gas pipeline systems in the absence of internal pressure.

*** For gas pipeline systems ( $10 \%$ to $90 \%$ probability of limit state). 


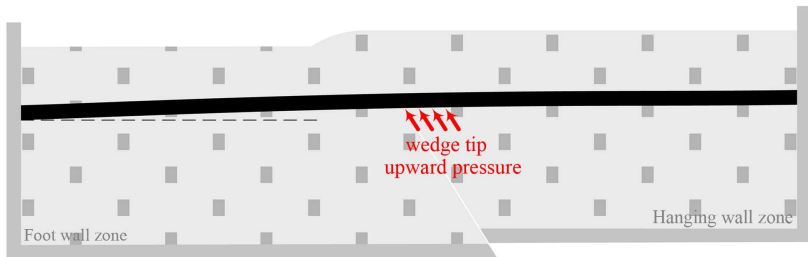

(a)

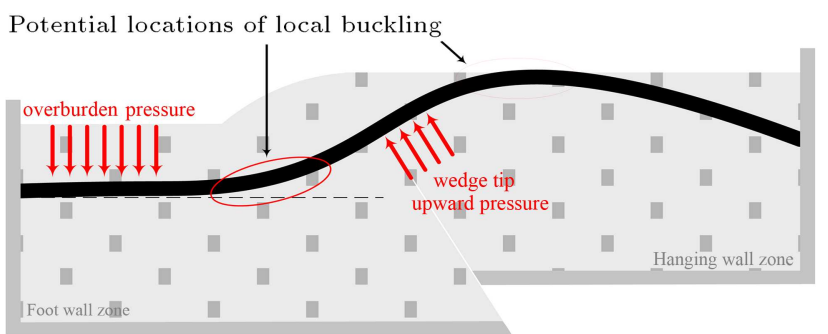

(b)

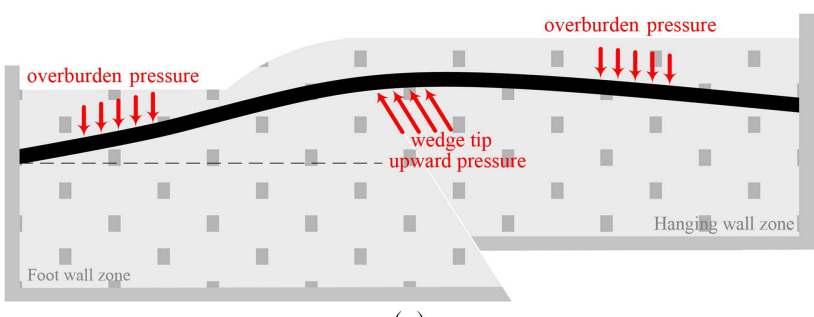

(c)

Figure 10. A schematic presentation of buckling phenomenon: (a) Buckling initiation, (b) local buckling evolution, and (c) beam buckling evolution. The size of pressure arrows schematically demonstrates the magnitude of soil pressure on pipe.

such a mechanism (Figure 10). First, a slight upward movement of the pipe has occurred in the footwall zone, whereas the hanging wall tip soil, underneath the pipe, pushes the pipeline upward, relatively (Figure 10(a)). Then, depending on the "relative burial depth", mostly effective in the footwall zone, and the pipe stiffness $(t / D)$, mostly impressing the hanging wall zone, the mechanism chooses between the local (Figure 10(b))

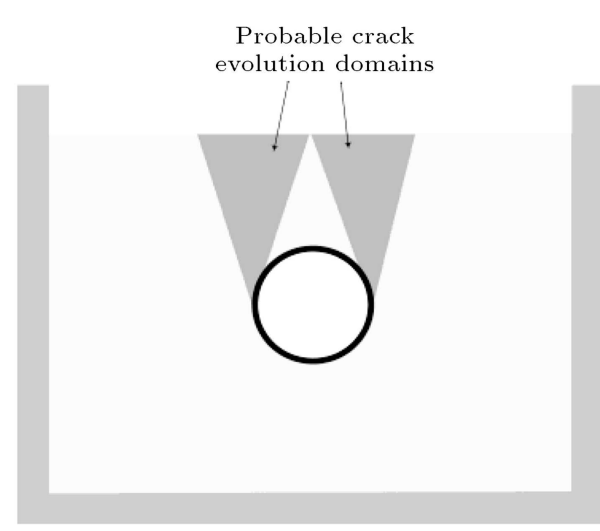

(a) or beam buckling (Figure 10(c)), respectively. Such a description of the phenomenon does not reject the influence of other factors, but definitely rejects the interpretation of the effects of the proposed ones.

As observed in the conducted tests, the rupture propagation due to upward movement of the pipe follows a similar pattern that is drawn schematically in Figure 11. Moreover, the soil has been cracked in a longitudinal pattern above and parallel to the pipe route.

\subsubsection{Axial and bending strains}

The axial strain distributions along the pipelines are shown in Figure 12. As shown in Table 1, the peak faulting offset applied to the specimens was around 1.15 $\mathrm{m} \sim 1.18 \mathrm{~m}$ (faulting offset could not exceed the applied magnitudes due to mechanical limitations of simulator box). The comparison of the reverse fixed end connection tests of the current study with the reverse tests conducted by Rojhani et al. [24] demonstrates different axial distributions for footwall zone in somehow similar conditions. This could be due to the mild behavior of welded areas of end connections in the research of Rojhani et al. [24] that absorbed a significant portion of compressive strain and, eventually, affected the strain distribution along the pipeline. Based on the results

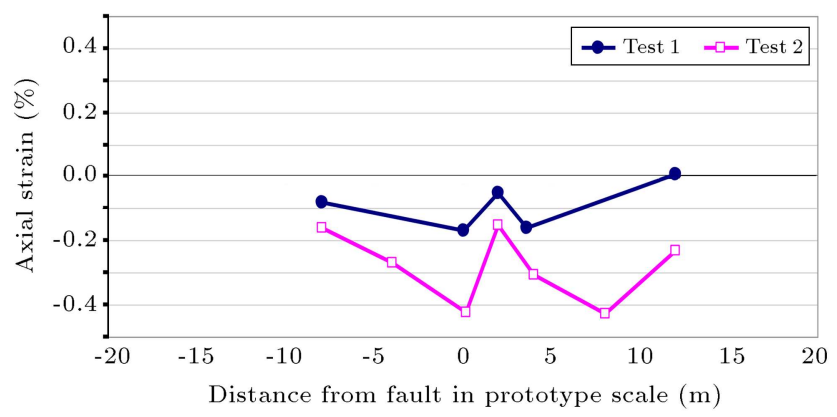

Figure 12. Axial strain distribution along the pipeline for fault offset of $1.15 \mathrm{~m}$ in a prototype scale.

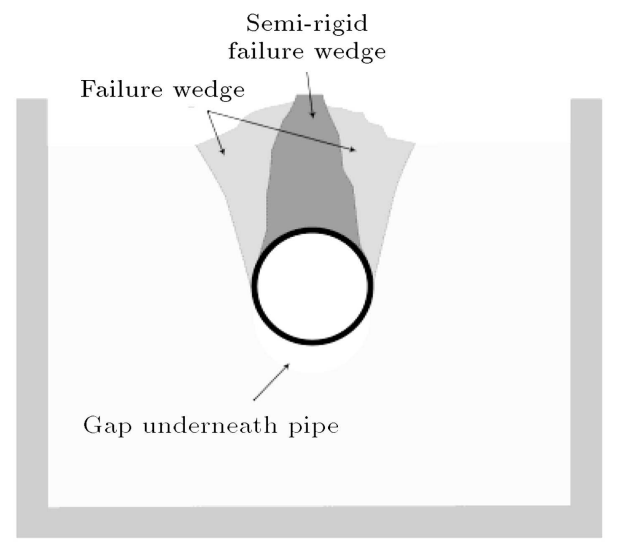

(b)

Figure 11. Soil section, schematically demonstrating crack propagation: (a) Before crack initiation and (b) after crack evolution. 


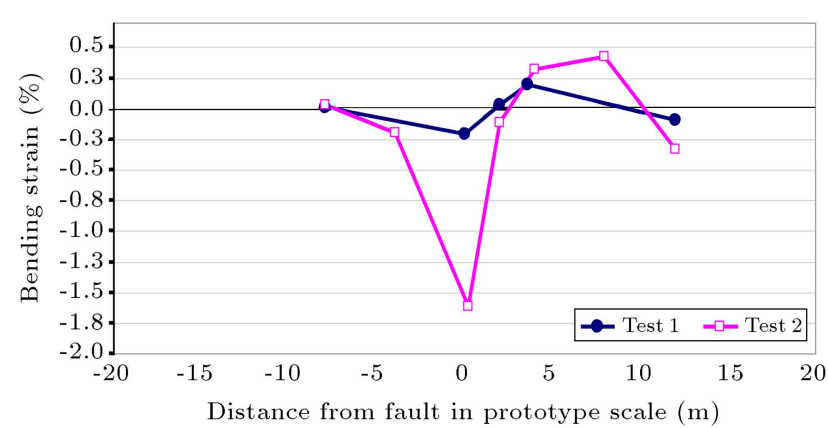

Figure 13. Bending strain distribution along the pipeline for fault offset of $1.15 \mathrm{~m}$ in a prototype scale.

depicted in diagrams of Figure 12, both pipelines have demonstrated compressive axial behavior due to reverse faulting. In both conducted tests (Tests 1 and 2), the compressive strain distribution has formed "W" shaped diagrams. Considering that the critical zone of compression was located adjacent to the fault plane in the footwall zone, the accurate location of maximum compressive strain could not be determined accurately due to the limited number of installed strain gauges. Moreover, the pipeline of Test 2 has generally experienced a higher level of compressive axial strain due to the lower axial stiffness compared to the pipeline of Test 1.

According to the bending diagrams (Figure 13), the pipeline in Test 2 experienced higher bending strain magnitudes as compared to the pipeline in Test 1 regarding the lower bending stiffness of the pipeline of Test 2. The accurate magnitude of the peak bending strain could not be specified due to the limited number of installed strain gauges. However, through the bending strain distribution trends, it could be deduced that such a strain would develop adjacent to the faulting plane in the footwall zone.

\section{Local buckling}

When the pipeline is subjected to compression, it might experience local instability. This type of failure is a common mode for steel pipe damages [10,50] and can be considered as a limit state. Such a phenomenon is called local buckling (wrinkling) and initiates when the compression strain exceeds a certain limit called critical strain $\left(\epsilon_{c r}\right)$. Various studies and guidelines have proposed different criteria for critical strain, compared with the extremum logged strains of Tests 1 and 2 in Table 4. Such extremum strains did not necessarily represent the pipeline peak strains as a limited number of employed instruments.

According to Table 4, the pipeline employed in Test 1 did not reach the critical strain limit and, eventually, did not experience local buckling as seen in Figure 9(c). However, the pipeline of Test 2 has reached the critical strain limits, and wrinkling can be observed in Figures 9(d) and 14.

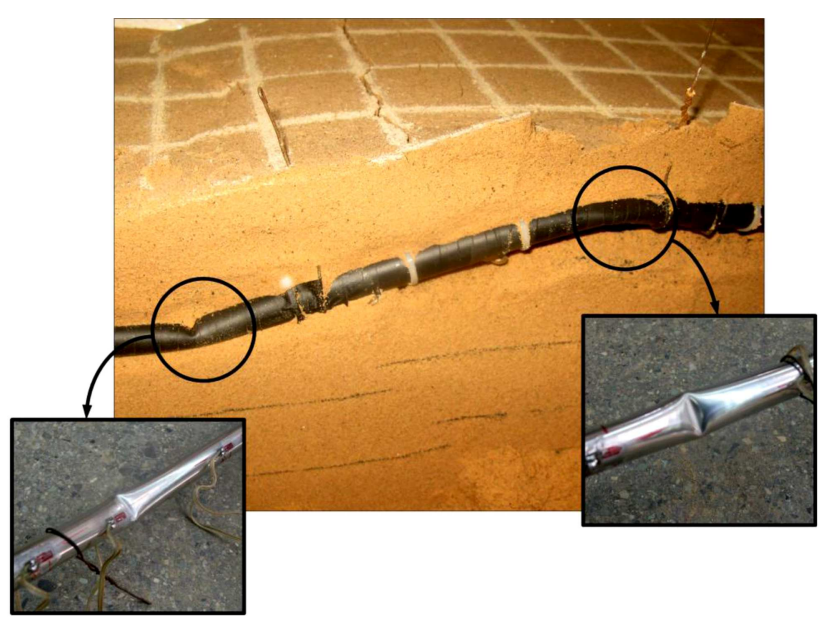

Figure 14. Wrinkling of the pipe due to faulting in Test 2 .

The top and bottom fiber recorded strains of Test 2 are depicted in Figure 15, for which wrinkling did happen. A detailed strain investigation of the top and bottom fibers of the pipes revealed that the pipe initially experienced compression along its almost entire length when subjected to reverse faulting. When a particle of the pipeline wall reaches the wrinkling onset, the strain localization may happen, and the strain distribution changes along the pipeline. Eventually, the compressive strain concentrated around the wrinkled area (strain localization) and the strain distribution tended towards zero (say "strain releasing") for other pipe elements.

\subsection{Numerical model}

As indicated, the behavior of the developed numerical model was compared with that of the corresponding centrifuge tests in Table 1 as the next step of the research. By employing an evolutionary algorithm [52] in MATLAB software, the numerical model parameters were set properly to calibrate the numerical model in a calibration process. The diagrams depicted in Figures 16 and 17 demonstrate the comparison of axial and bending strains of numerical simulation with the results of the reference centrifuge tests of Table 1 . The numerical model dimensions were set in accordance with the dimensions of the centrifuge tests.

As shown in Figures 16 and 17, the axial and bending strain diagrams demonstrate good agreement (less than $5 \%$ difference) with those of centrifuge tests. Considering such convincing agreement between experimental and numerical results, the calibrated numerical model was longitudinally extended in order to cover the whole fault-affected length of pipe. With the aid of such an extended numerical model, the desired internal forces and displacements of the model sections corresponding to the box end connection displacements and reaction forces were obtained. Then, with the aid of such data, the spring-like end connection systems 


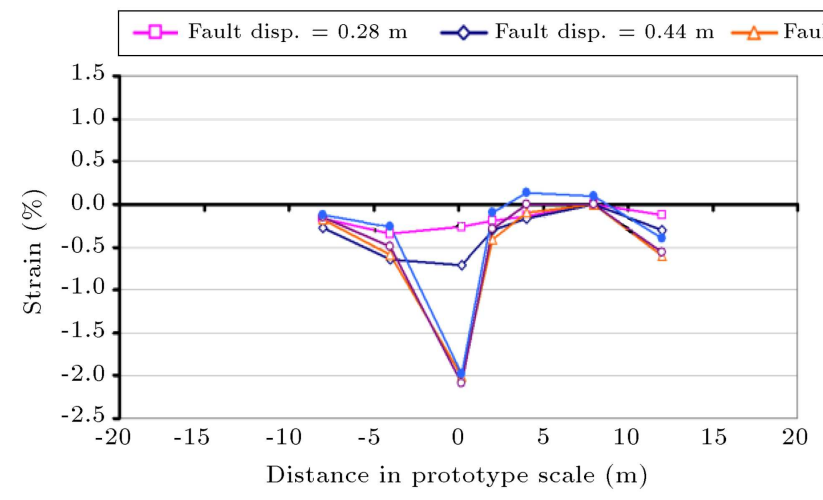

(a)

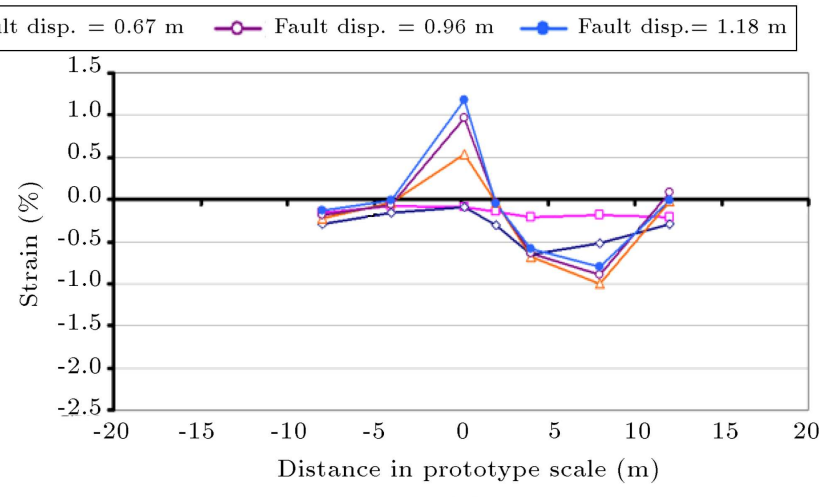

(b)

Figure 15. Strain distribution along the top (a) and bottom (b) fibers of Test 2 pipeline.

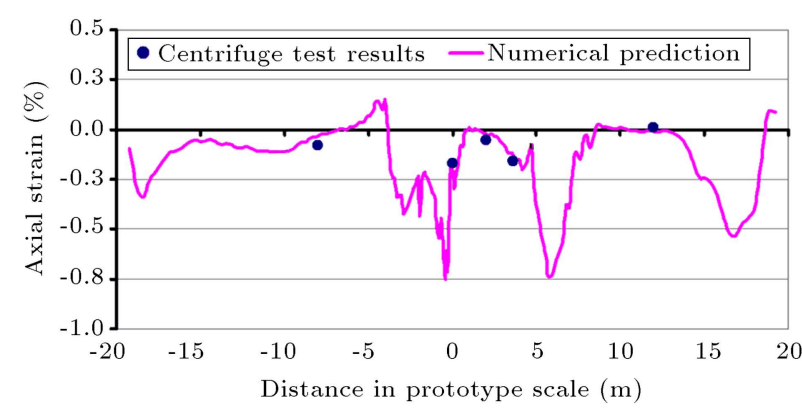

(a)

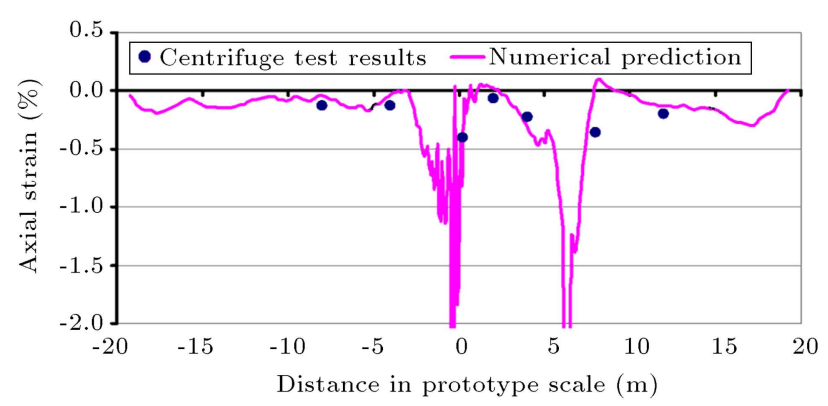

(b)

Figure 16. Axial strain comparison with corresponding numerical model: (a) Test 1 and (b) Test 2.

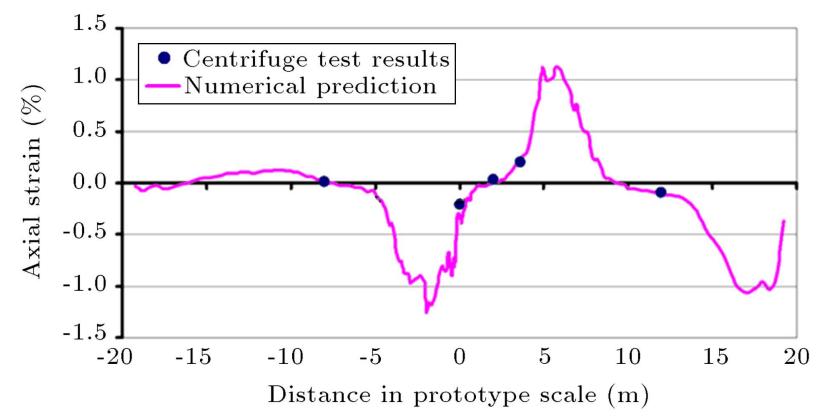

(a)

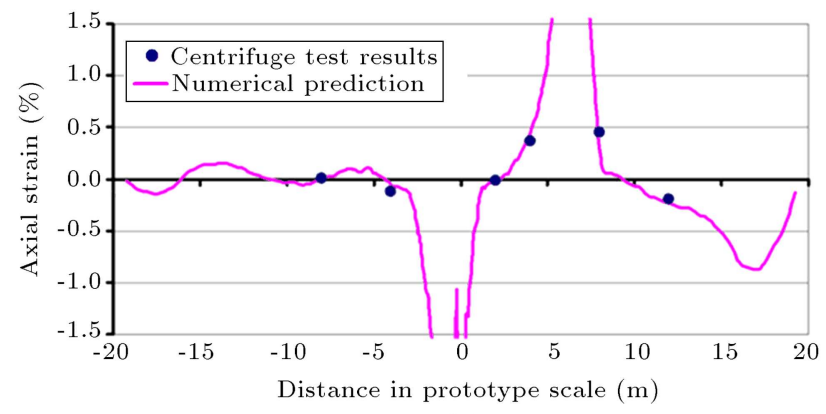

(b)

Figure 17. Bending strain comparison with corresponding numerical model: (a) Test 1 and (b) Test 2.

were designed to be employed to verify Test 3 of Table 1.

\section{3. "Spring-like end connection" centrifuge tests}

An individual test (Test 3 of Table 1) was conducted on reverse faulting mechanisms in order to verify the numerical model calibration process and also the performance of the designed spring-like end connection systems. The result of such a centrifuge test was compared with that of an extended numerical model; then, the responses of models were discussed.

\subsubsection{Models response comparison}

Three categories of comparison were conducted through the instruments. First, the results of strain gauges, installed on top and bottom fibers of pipes, were compared with those of the extended numerical model ones in Figure 18.

As seen in Figure 18, the numerical model's results generally showed good agreement with the strain results of centrifuge model. In the bottom fiber strain distribution diagram of a reverse centrifuge test (Figure 18, pointed by arrow), where it almost touches the tip of the faulting wedge, a strain gauge appeared to be malfunctioning, probably due to the earth upward pressure on the pipeline or the adhesion defect due to wrinkling initiation. Moreover, all other strain gauges logged convincing magnitudes of strain, complying with numerical model results. As the second data 
Table 5. Numerical-experimental displacement* comparison in three pipe sections.

\begin{tabular}{ccccc}
\hline Section no. & Section location on pipe & \multicolumn{3}{c}{ Reverse faulting test } \\
\cline { 3 - 5 } & & Exp. $(\mathbf{m})$ & Num. $(\mathbf{m})$ & Deviation $^{\text {** }}(\mathbf{\%})$ \\
\hline 1 & Mid foot wall zone & 0.307 & 0.333 & $\mathbf{8 . 7 \%}$ \\
2 & Fault plane intersection & 0.436 & 0.451 & $\mathbf{3 . 3 \%}$ \\
3 & Mid hanging wall zone & 0.224 & 0.243 & $\mathbf{8 . 4 \%}$ \\
\hline
\end{tabular}

* All displacement magnitudes are offered on a prototype scale.

** Deviation indicates the percentage ratio of the numerical result to the centrifuge test deviation.

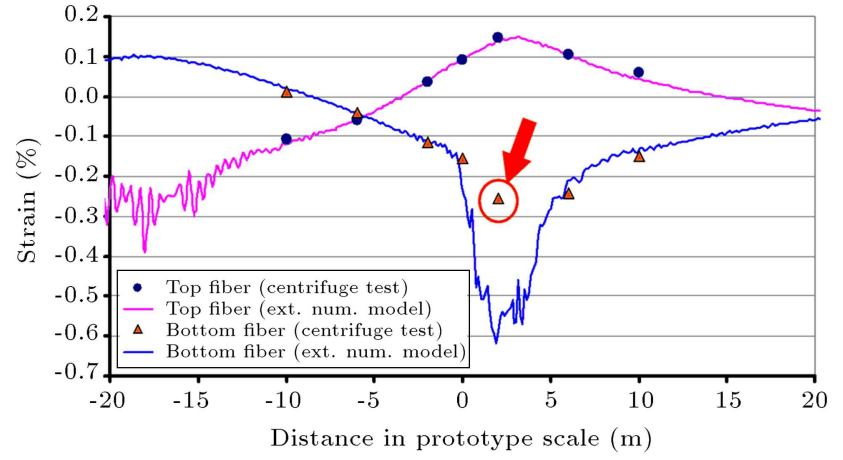

Figure 18. Reverse faulting strain distribution comparison along the pipeline for experimental and numerical tests.

acquisition approach, the pipeline displacements of three sections located in hanging wall zone, intersection of pipe-fault plane, and footwall zone were monitored with the aid of wire LVDTs. As indicated in Table 5, all the calibrated numerical model results had less than $10 \%$ deviation from the logged displacements of centrifuge models, which could be a convincing approximation for the numerical model.

Moreover, the pipe displacements in the springlike end connection systems were measured with the aid of image processing through the before-after pictures taken form the displacements and rotations that occurred due to faulting movement in the end connection systems. The before-after pictures of foot and hanging end connections for the reverse faulting mechanisms are depicted in Figure 19.

According to the comparison of the results, indicated in Table 6, there is good agreement between the numerical results with the captured end connection movements. All the above verification results certify that the method proposed in this study can be used to obtain a full-scale response of employed pipelines with the small-scale centrifuge modelling approach. In other words, the limitation of the centrifuge modelling dimension was eliminated in the current study with the aid of spring-like end connection approach. Such an approach could be employed in the experimental evaluation of novel researches such as new mitigation techniques, where the benchmark physical models are required.
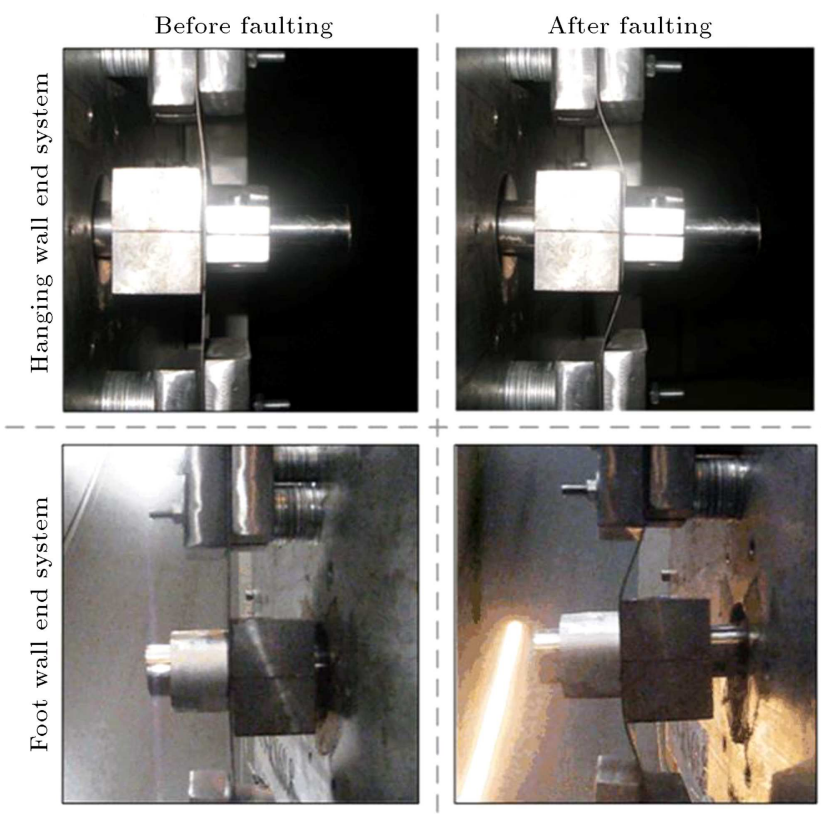

Figure 19. The before-after movement pictures of hanging wall and footwall zones for reverse faulting.

In the following, the results of the new developed centrifuge models are discussed as a small-scale "nonlimited length" model in which the results would correspond to the full-scale model.

\subsubsection{Axial and bending strains}

The diagrams of pipeline axial and bending strain distribution for fixed and spring-like end connection systems are depicted in Figure 20. The axial strain distribution (Figure 20(a)) reveals that the pipes generally experienced compressive mode in reverse faulting. The pipes in fixed end tests were more prepared for wrinkling initiation than the pipes in spring-like end connection tests due to higher orders of compressive strain (Figures 12 and 13). For instance, the wrinkling did occur in Test 2 of Table 1. Moreover, the bending strain distribution was more concentrated in the region adjacent to the faulting plane with higher magnitudes of bending strain for pipelines in fixed end connection tests, while the bending strain distribution for pipeline of spring-like end connection test was significantly milder and without sharp extremums (Figure 20(b)). In other words, the reverse faulting effects on pipelines 
Table 6. Numerical-experimental displacement* comparison in end connection systems.

\begin{tabular}{|c|c|c|c|c|c|c|c|c|c|c|}
\hline \multirow[t]{2}{*}{$\begin{array}{l}\text { Fault } \\
\text { type }\end{array}$} & \multirow[t]{2}{*}{$\begin{array}{c}\text { End } \\
\text { connection }\end{array}$} & \multicolumn{3}{|c|}{$\begin{array}{l}\text { Longitudinal } \\
\text { displacement } \\
\left(\Delta d_{h}\right)\end{array}$} & \multicolumn{3}{|c|}{$\begin{array}{c}\text { Vertical transverse } \\
\text { displacement } \\
\left(\Delta d_{v}\right)\end{array}$} & \multicolumn{3}{|c|}{$\begin{array}{c}\text { Rotation } \\
\text { angle } \\
\theta\end{array}$} \\
\hline & & $\begin{array}{c}\text { Exp. } \\
(\mathrm{m})\end{array}$ & $\begin{array}{c}\text { Num. } \\
(\mathrm{m})\end{array}$ & $\begin{array}{c}\text { Deviation }^{* *} \\
(\%)\end{array}$ & $\begin{array}{c}\text { Exp. } \\
(\mathbf{m})\end{array}$ & $\begin{array}{l}\text { Num. } \\
(\mathbf{m})\end{array}$ & $\begin{array}{c}\text { Deviation }^{* *} \\
(\%)\end{array}$ & $\begin{array}{c}\text { Exp. } \\
\left({ }^{\circ}\right)\end{array}$ & $\begin{array}{c}\text { Num. } \\
\left({ }^{\circ}\right)\end{array}$ & $\begin{array}{c}\text { Deviation }{ }^{* *} \\
(\%)\end{array}$ \\
\hline \multirow{2}{*}{ Reverse } & Foot wall & 0.423 & 0.469 & $10.8 \%$ & 0.025 & 0.026 & $4.3 \%$ & 1.026 & 0.935 & $8.9 \%$ \\
\hline & Hanging wall & 0.264 & 0.238 & $9.9 \%$ & 0.066 & 0.072 & $9.4 \%$ & 0.0 & 0.002 & - \\
\hline
\end{tabular}

* All displacement magnitudes are offered on a prototype scale.

** Deviation indicates the percentage ratio of the numerical result to the centrifuge test deviation.

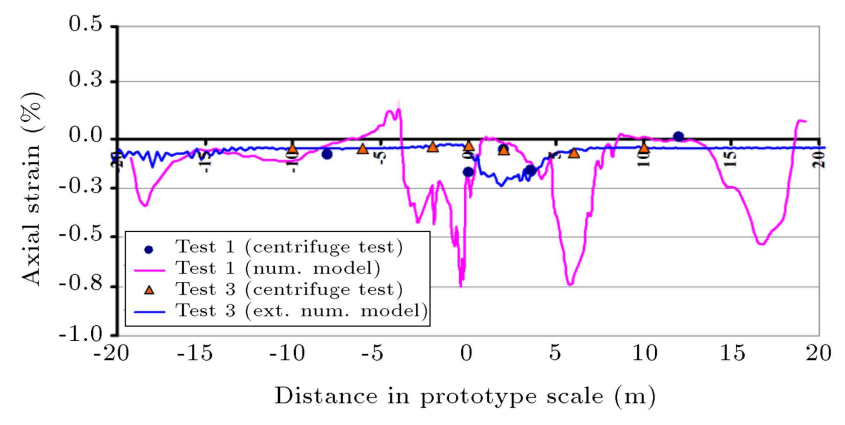

(a)

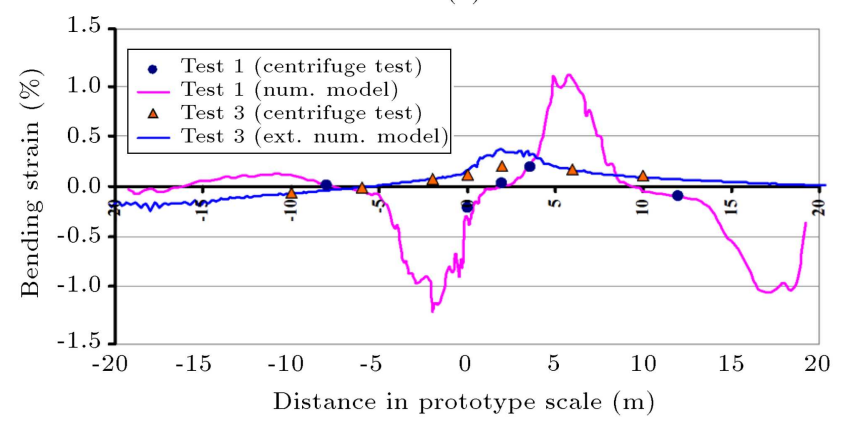

(b)

Figure 20. The pipeline axial (a) and bending (b) strain comparison for fixed and spring-like end connection system models subjected to the reverse faulting.

would be much milder in a full pipeline's affected length mechanism than in a limited-length fixed end mechanism.

\subsubsection{Pipeline rupture}

According to the strain-based pipeline design procedure (see Section 4.1.2), strain distributions of the top and bottom fibers (Figure 18) could be compared with the allowable tensile and compressive limit strains. As could be seen, none of the pipelines touched the tensile limit strain (pressure integrity limit) of $4 \%$ [51]; therefore, both of them could be maintained in an operation regarding this criterion. Moreover, the bottom fiber of pipeline subjected to the reverse faulting (Figure 18) experienced wrinkling initiation as the strain distribution exceeded the compression limit strain of $1.0 \%$. The visual inspection of the pipeline of Test 3 of Table 1 showed no defect in the pipeline, and the pipeline could be permitted to experience higher levels of compressive strains.

\section{Conclusions}

Using a combination procedure of centrifuge and numerical modelling, the response of steel buried pipelines subjected to reverse faulting was studied. Initially, two centrifuge tests with fixed end connections were performed. Then, a calibrated numerical model was developed based on the reference centrifuge test's results. In the next step, a "spring-like" end connection was developed in this study and employed in a distinct centrifuge test in order to overcome the geometrical limitations of small-scale centrifuge modelling. The following conclusions can be made from the experimental and numerical results:

- According to the visual observations, the soil underneath the pipes in hanging wall region acted like the cantilever supports for the pipe in reverse faulting mechanisms;

- Subjected to reverse faulting, the pipelines with fixed end connections experienced compression, while the dominant response of the pipes was bending. Considering the proposed compressive strain limits, the pipelines would behave between either beam or local buckling. The pipeline reaching the compressive strain limit (Test 2) in the top and bottom fibers experienced an apparent local buckling (wrinkling), while the other model pipeline (Test 1) did not exceed the limits and just approached the buckling initiation limits;

- The reverse centrifuge tests' results revealed that the parameters of "relative burial depth" $(H / D)$ and the "relative fault displacement" $(U / D)$ might also play a role in forming the type of pipeline buckling, apart from the previously proposed factors such as the pipe wall thickness-to-diameter ratio $(t / D)$; 
- Longitudinal extension of the numerical model demonstrated that the pipeline would experience much lower levels of strains in the full-scale numerical simulation than in the fixed end pipeline simulation;

- Convincing agreement of the results of the "springlike" pipeline end connection centrifuge test with those of the numerical simulation indicated that such a combined small-scale numerical modelling approach could be employed to overcome the geometrical limitation of the small-scale centrifuge tests, and such a "spring-like" centrifuge model could represent the "full pipeline length modelled" mechanism;

- Having a limited space for rotation of end connection systems, pipelines with bigger diameters should be used with further investigation, employing such a combined approach;

- In a reverse faulting mechanism, the "spring-like" centrifuge model results showed lower orders of compressive strain, compared to the fixed end centrifuge models. Moreover, the bending strain distribution was more concentrated in the region adjacent to the faulting plane with higher magnitudes of bending strain for pipelines in fixed end connection tests, while the bending strain distribution for pipeline of spring-like end connection test was significantly smoother and without sharp extremums.

\section{Acknowledgment}

The authors would like to appreciate the opportunity to acknowledge the Physical Modeling and Centrifuge Laboratory of the Soil Mechanics and Foundation Engineering Department, School of Civil Engineering, University of Tehran. The authors would like to express their thanks and deep gratitude to the personnel and laboratory experts including Mr. Salimi, Mr. Shakouri, and Mr. Jabbarzadeh for their assistance.

\section{References}

1. Sim, W.W., Towhata, I., Yamada, S., and Moinet, G.M. "Shaking table tests modelling small diameter pipes crossing a vertical fault", Soil Dynamics and Earthquake Engineering, 35, pp. 59-71 (2012).

2. Newmark, N.M. and Hall, W.J., "Pipeline design to resist large fault displacement", Proceedings of U.S. National Conference on Earthquake Engineering, USA, pp. 416-425 (1975).

3. Kennedy, R.P., Chow, A.M., and Williamson, R.A. "Fault movement effects on buried oil pipeline", Transportation Engineering Journal of the American Society of Civil Engineers, 103(5), pp. 617-633 (1977).
4. Wang, L.R.L. and Yeh, Y. "A refined seismic analysis and design of buried pipeline for fault movement", Journal of Earthquake Engineering and Structural Dynamics, 13, pp. 75-96 (1985).

5. Meyersohn, W.D., Analytical and Design Considerations for the Seismic Response of Buried Pipelines, Cornell University, New York, USA (1991).

6. Takada, S., Hassani, N., and Fukuda, K., "A new proposal for simplified design of buried steel pipes crossing active faults", Earthquake Engineering \& Structural Dynamics, 30(8), pp. 1243-1257 (2001).

7. Kuwata, Y., Takada, S., and Ivanov, R. "DEM response analysis of buried pipelines crossing faults and proposal for a simplified method to estimate allowable fault displacements", Journal of Seismology and Earthquake Engineering, 9(4), pp. 195-201 (2007).

8. Vazouras, P., Karamanos, S.A., and Dakoulas, P. "Finite element analysis of buried steel pipelines under strike-slip fault displacements", Soil Dynamics and Earthquake Engineering, 30(11), pp. 1361-1376 (2010).

9. Karamitros, D.K., Bouckovalas, G.D., Kouretzis, G.P., and Gkesouli, V. "An analytical method for strength verification of buried steel pipelines at normal fault crossings", Soil Dynamics and Earthquake Engineering, 31(11), pp. 1452-1464 (2011).

10. Vazouras, P., Karamanos, S.A., and Dakoulas, P. "Mechanical behavior of buried steel pipes crossing active strike-slip faults", Soil Dynamics and Earthquake Engineering, 41, pp. 164-180 (2012).

11. Xie, X., Symans, M.D., O'Rourke, M.J., Abdoun, T.H., O'Rourke, T.D., Palmer, M.C., and Stewart, H.E. "Numerical modeling of buried HDPE pipelines subjected to strike-slip faulting", Journal of Earthquake Engineering, 15(8), pp. 1273-1296 (2011).

12. Xie, X., Symans, M.D., O'Rourke, M.J., Abdoun, T.H., O'Rourke, T.D., Palmer, M.C., and Stewart, H.E. "Numerical modeling of buried HDPE pipelines subjected to normal faulting: a case study", Earthquake Spectra, 29(2), pp. 609-632 (2013).

13. Zhang, J., Liang, Z., and Han, C.J. "Buckling behavior analysis of buried gas pipeline under strike-slip fault displacement", Journal of Natural Gas Science and Engineering, 21, pp. 921-928 (2014).

14. Rahman, M.A. and Taniyama, H. "Analysis of a buried pipeline subjected to fault displacement: A DEM and FEM study", Soil Dynamics and Earthquake Engineering, 71, pp. 49-62 (2015).

15. Vazouras, P., Dakoulas, P., and Karamanos, S.A. "Pipe-soil interaction and pipeline performance under strike-slip fault movements", Soil Dyn. Earthq. Eng., 72, pp. 48-65 (2015).

16. Audibert, J.M. and Nyman, K.J. "Soil restraint against horizontal motion of pipes", Journal of the Geotechnical Engineering Division, 103(10), pp. 11191142 (1977). 
17. Takada, S. "Model analysis and experimental study on mechanical behavior of buried ductile iron pipeline subjected to large ground deformation", Proceeding of 8th World Conference on Earthquake Engineering, San Francisco, California, USA, pp. 255-262 (1984).

18. O'Rourke, M., Gadicherla, V., and Abdoun, T. "Centrifuge modeling of buried pipelines", In Advancing Mitigation Technologies and Disaster Response for Lifeline Systems, ASCE Press, USA, pp. 757-768 (2003).

19. O'Rourke, M., Gadicherla, V., and Abdoun, T. "Centrifuge modeling of PGD response of buried pipe", Earthquake Engineering and Engineering Vibration, 4(1), pp. 69-73 (2005).

20. Choo, Y.W., Abdoun, T.H., O’Rourke, M.J., and Ha, D. "Remediation for buried pipeline systems under permanent ground deformation", Soil Dynamics and Earthquake Engineering, 27(12), pp. 1043-1055 (2007).

21. Ha, D., Abdoun, T., O'Rourke, M., Symans, M., O'Rourke, T., Palmer, M., and Stewart, H. "Centrifuge modeling of permanent ground deformation effect on buried HDPE pipelines", Journal of Geotechnical and Geoenvironmental Engineering, 134(10), pp. 15011515 (2008).

22. Ha, D., Abdoun, T.H., O’Rourke, M.J., Symans, M.D., O'Rourke, T.D., Palmer, M.C., and Stewart, H.E. "Buried high-density polyethylene pipelines subjected to normal and strike-slip faulting-a centrifuge investigation", Canadian Geotechnical Journal, 45(12), pp. 1733-1742 (2008).

23. Ha, D., Abdoun, T.H., O'Rourke, M.J., Symans, M.D., O'Rourke, T.D., Palmer, M.C., and Stewart, H.E. "Earthquake faulting effects on buried pipelines-case history and centrifuge study", Journal of Earthquake Engineering, 14(5), pp. 646-669 (2010).

24. Rojhani, M., Moradi, M., Galandarzadeh, A., and Takada, S. "Centrifuge modeling of buried continuous pipelines subjected to reverse faulting", Canadian Geotechnical Journal, 49(6), pp. 659-670 (2012).

25. Rojhani, M., Moradi, M., Ebrahimi, M.H., Galandarzadeh, A., and Takada, S. "Recent developments in faulting simulators for geotechnical centrifuges", ASTM Geotechnical Testing Journal, 35(6), pp. 924934 (2012).

26. Moradi, M., Rojhani, M., Galandarzadeh, A., and Takada, S. "Centrifuge modeling of buried continuous pipelines subjected to normal faulting", Earthquake Engineering and Engineering Vibration, 12(1), pp. 155-164 (2013).

27. Hojjat Jalali, H., Rofooei, F.R., Attari, N.K.A., and Samadian, M., "Experimental and finite element study of the reverse faulting effects on buried continuous steel gas pipelines", Soil Dynamics and Earthquake Engineering, 86, pp. 1-14 (2016).
28. Choo, Y.W., Abdoun, T.H., O'Rourke, M.J., and Ha, D. "Remediation for buried pipeline systems under permanent ground deformation", Soil Dynamics and Earthquake Engineering, 27(12), pp. 1043-1055 (2007).

29. Melissianos, V.E., Korakitis, G.P., Gantes, C.J., and Bouckovalas, G.D. "Numerical evaluation of the effectiveness of flexible joints in buried pipelines subjected to strike-slip fault rupture", Soil Dynamics and Earthquake Engineering, 90, pp. 395-410 (2016).

30. Vazouras, P., Dakoulas, P., and Karamanos, S.A. "Pipe-oil interaction and pipeline performance under strike-slip fault movements", Soil Dynamics and Earthquake Engineering, 72, pp. 48-65 (2015).

31. Zhang, L., Zhao, X., Yan, X., and Yang, X. "A new finite element model of buried steel pipelines crossing strike-slip faults considering equivalent boundary springs", Engineering Structures, 123, pp. 30-44 (2016).

32. ASTM A999/A999M-16 "Standard specification for general requirements for alloy and stainless steel pipe", ASTM International, West Conshohocken, PA, USA (2016).

33. Moosbrugger, C., Atlas of Stress-Strain Curves, ASM International Press, Ohio, USA, p. 299 (2002).

34. Ovesen, N.K. "Centrifuge tests of the uplift capacity of anchors", Proceedings of the 10th International Conference on Soil Mechanics and Foundation Engineering, Stockholm, Sweden, pp. 717-722 (1981).

35. Dickin, E.A. and Leuoy, C.F. "Centrifuge model tests on vertical anchor plates", ASCE Journal of Geotechnical Engineering, 109(12), pp. 1503-1525 (1983).

36. Garnier, J., Gaudin, C., Springman, S.M., Culligan, P.J., Goodings, D., Kutter, B., and Thorel, L. "Catalogue of scaling laws and similitude questions in centrifuge modeling", Report Technical Committee TC2, Physical Modelling in Geotechnics (2005).

37. Gresnigt, A.M., Plastic Design of Buried Steel Pipelines in Settlement Areas, TNO-Institute for Building Materials and RIJSWIJK, The Netherlands (1987).

38. Gresnigt, A.M. and Karamanos, S.A. "Local buckling strength and deformation capacity of pipes", The Nineteenth International Offshore and Polar Engineering Conference, Osaka, Japan, pp. 36-44 (2009).

39. Canadian Standard Association, Oil and Gas Pipeline Systems, Code CSA-Z662, Mississauga, Ontario, Canada (2007).

40. ABAQUS "Users' Manual", Dassault Systemes Simulia, Providence, RI, USA (2010).

41. Bray, J.D., Seed, R.B., and Seed, H.B. "1g small-scale modeling of saturated cohesive soils", Geotech. Test. $J .$, 16(1), pp. 46-53 (1993).

42. Anastasopoulos, I., Gazetas, G., Bransby, M.F., Davies, M.C.R., and El. Nahas, A. "Fault rupture propagation through sand: Finite-element analysis and validation through centrifuge experiments", Journal 
of Geotechnical and Geoenvironmental Engineering, 133(8), pp. 943-958 (2007).

43. Potts, D.M., Dounias, G.T., and Vaughan, P.R. "Finite element analysis of progressive failure of Carsington embankment", Geotechnique, 40(1), pp. 79-101 (1990).

44. Yoshimi, Y. and Kishida, T. "Ring torsion apparatus for evaluating friction between soil and metal surfaces", Geotech. Test. J., 4(4), pp. 145-152 (1981).

45. Yimsiri, S., Soga, K., Yoshizaki, K., Dasari, G.R., and O'Rourke, T.D. "Lateral and upward soil-pipeline interactions in sand for deep embedment conditions", Journal of Geotechnical and Geoenvironmental Engineering, 130(8), pp. 830-842 (2004).

46. Peng, L.C. "Stress analysis methods for underground pipe lines", Pipe Line Ind., 47(5), pp. 65-74 (1978).

47. Yun, H.D. and Kyriakides, S. "On the beam and shell modes of buckling of buried pipelines", Soil Dyn. Earthq. Eng., 9(4), pp. 179-93 (1990).

48. Meyersohn, W.D., Analytical and Design Considerations for the Seismic Response of Buried Pipelines, Cornell University, New York, USA (1991).

49. O'Rourke, M.J. and Liu, X. "Seismic design of buried and offshore pipelines", Report MCEER Monograph MCEER-12-MN04, University of Buffalo, New York, USA (2012).

50. A.L.A., Guidelines for the Design of Buried Steel Pipe, American Society of Civil Engineers, USA (2001).

51. Wijewickreme, D., Honegger, D., Mitchell, A., and Fitzell, T. "Seismic vulnerability assessment and retrofit of a major natural gas pipeline system: a case history", Earthquake spectra, 21(2), pp. 539-567 (2005).

52. Sharifi-Noghabi, H., Mashhadi, H.R., and Shojaee, K. "A novel mutation operator based on the union of fitness and design spaces information for differential evolution", Soft Computing, pp. 1-8 (2016).

\section{Biographies}

Reza Yeganeh Khaksar is a PhD Student in Geotechnical Engineering, studying in the Civil Engineering Faculty of University of Tehran. He has received his MSc degree in Geotechnical Engineering and, currently, is studying the response of buried pipelines subjected to faulting in his $\mathrm{PhD}$ thesis research. Through this study, he has conducted experimental centrifuge modelling of buried pipelines due to faulting together with related numerical modellings. Through such a study, he has published articles in some international journals and conferences. More results of the research are submitted to be published in some ISI journals.

Majid Moradi is an Assistant Professor at the Geotechnical Engineering Department in the Civil Engineering Faculty of University of Tehran. He has broad experience in physical modelling in geotechnics, especially employing geotechnical centrifuge facility. Moreover, he has supervised numerous MSc and PhD students with the research subject of the physical and numerical modellings. Recently, he has led a series of centrifuge and numerical modelling studies on the response of buried pipelines subjected to faulting, through which some postgraduate students have been employed and the articles have been published.

Abbas Ghalandarzadeh is an Associate Professor at the Geotechnical Engineering Department in the Civil Engineering Faculty of University of Tehran. Aside from being a well-known academic character in experimental researches in geotechnics, he is also the manager of the unique "Soil Dynamics and Physical Modelling" laboratory of the Civil Engineering Faculty of University of Tehran. He has conducted numerous experimental researches in geotechnics and, currently, is facilitating an advanced "Soil Dynamics" laboratory for the University of Tehran. 